\title{
CH. MOUFFE Y E. LACLAU: UNA LECTURA DE LOS APORTES DE LUDWIG WITTGENSTEIN PARA PENSAR LA IDEA DE DEMOCRACIA RADICAL Y PLURAL
}

\section{Mirta A. Giacaglia*}

En un mundo cada vez más interdependiente y fragmentado, la problemática de las identidades, la diferencia y la multiplicidad constituye uno de los temas centrales en orden a reflexionar sobre la posibilidad de construcción de una democracia radical y plural, en la cual sea posible articular los principios de la libertad y justicia con la cuestión de la diversidad cultural, entendida ésta no como discriminación sino como la plena aceptación del otro en tanto otro, y no sólo en tanto se subordine a nuestros parámetros culturales. Para abordar dichas cuestiones desde nuestro presente paradójico y conflictivo, volver la mirada al pensamiento de Ludwig Wittgenstein (quien ya en la primera mitad del siglo XX se abocó a la tarea de desmontar el lenguaje cotidiano, las prácticas y las formas de vida, rechazando la construcción de conceptos universales y abstractos, y asumiendo este desafío como un acto ético radical), nos proporciona una perspectiva sumamente enriquecedora y productiva.

Nos proponemos en el presente trabajo tomar algunas de las categorías centrales de Wittgenstein, para lo cual creemos necesario hacer una primera reflexión sobre su tiempo y su vida, ya que entendemos que sólo a partir de estas coordenadas pueden comprenderse las ideas de un pensador, para luego analizar la lectura que Ernesto Laclau y Chantal Mouffe hacen de esos conceptos wittgenstenianos a fin de pensar y elaborar su teoría de discurso y la idea de democracia radical y plural, en un mundo donde la pérdida de valor de la palabra y la hipocrecía también desencadenan grandes tragedias.

\footnotetext{
* Profesora de la Universidad Nac. de Entre Ríos, Paraná (artemiag@infovia.com.ar).
} 


\section{Wittgenstein: su vida, su tiempo y sus preocupaciones éticas}

La preocupación que atraviesa toda la vida de Wittgenstein (y este es uno de esos pensadores en los que muy especialmente pensamiento y vida pasan a ser una misma cosa) es la de conocer la naturaleza y los límites del lenguaje en relación a sus inquietudes intelectuales $\mathrm{y}$, fundamentalmente, éticas, en medio de una sociedad, el Imperio Austro-Húngaro, corrompida y desesperanzada que se debate entre múltiples identidades en pugna, en la cual toda comunicación es fallida y ambigua y la vida se consume en la artificialidad de una cultura que erige barreras para impedir la discusión de los graves problemas que la devastan. Bajo la máscara del lujo y la felicidad se extendían la corrupción y la pobreza. En medio del superficial esplendor de esa Viena que se derrumba al son del vals (esa "ciudad de ensueños" y al mismo tiempo "campo de pruebas de la destrucción del mundo"), de las paradojas constitucionales y sociales que encarnaba la monarquía de los Habsburgo y su capital, de los problemas de identidad que desgarraban a los diferentes pueblos y nacionalidades sujetas al Imperio, y de los conflictos de comunicación y de lengua que se suscitan, Kraus en el periodismo, Loos en la arquitectura, Schönberg en la música y Wittgenstein en filosofía, intentaron una profunda crítica moral poniendo en cuestión esa cultura enferma a partir de los medios de expresión dominantes y sus fundamentos. La inadecuación entre las prácticas y los conceptos revelaban los límites propios de un lenguaje hipócrita y estereotipado. En ese contexto, no es extraño, entonces, que una de las más inquietantes paradojas de la Viena de inicios del siglo XX sea el hecho de que tanto la política de la solución final nazi como el sionismo encontraran allí las condiciones para su desarrollo.

La obra de Wittgenstein no puede comprenderse sino en el devenir de su vida, a partir de la especial atmósfera de su círculo familiar ${ }^{1}$ y de la historia de Europa en las primeras décadas del siglo XX. La experiencia en el frente durante la Primera Guerra Mundial y la influencia que ejercieron en él las lecturas de Kierkegaard y Tolstoy lo marcaron hondamente, profundizando su carácter retraído y su celo moral. Se convirtió en un hombre solitario, extremadamente exigente respecto de su integridad ética, practicante de una

\footnotetext{
${ }^{1}$ Los Wittgenstein eran una de las familias más ricas de Europa, y en su seno fluía el gusto por las artes (en especial la música), la cultura cosmopolita y un gran refinamiento.
} 
austeridad extrema asociada a la idea de un igualitarismo absoluto, que lo llevó a renunciar a todos sus bienes y a asumir en distintos momentos de su vida diferentes trabajos manuales, en tanto creía que las actividades intelectuales no constituían una tarea humanamente útil. Experimentaba odio y angustia ante el poder de la ciencia, el cual le hacía pensar que la humanidad se encaminaba hacia el desastre. Fue un pensador intempestivo, a pesar del éxito y la enorme difusión de sus ideas en su tiempo, en tanto fue mal o parcialmente interpretado. Como él mismo señala en medio de esos tiempos oscuros: 'Mi manera de pensar no es deseable en esta época, tengo que esforzarme y nadar contracorriente'?.

Para dar alguna respuesta a las cuestiones morales que lo afligían, Wittgenstein lleva adelante un trabajo corrosivo respecto de todo conocimiento sostenido en un fundamente trascendente, permitiendo así poner en cuestión toda concepción fundacionalista y esencialista Entiende la filosofía como actividad y no como cuerpo de doctrinas, dado que no tiene una función cognitiva. Por tanto el filósofo no debe pretender elaborar una teoría, un cuerpo doctrinal, sino llevar a cabo un trabajo deconstructivoterapéutico. Filósofo es, entonces, aquel que está siempre dispuesto a cambiar sus ideas, a desafiar lo establecido. Su hostilidad a la vida académica, en especial la de Cambridge, permiten comprender mejor aquello que alguna vez escribió: "Creo que resumi mi actitud respecto a la filosofía cuando dije: en realidad la filosofía debería escribirse como una composición poética";; otorga así al arte una importancia central en tanto sólo él puede expresar el significado de la vida y sitúa la ética en el ámbito del arte, fuera de la esfera racional. "La ética y la estética son una misma y sola cosa", la ética es condición del mundo: "La ética es trascendental's. El lenguaje no puede decirnos absolutamente nada de lo que es realmente importante: la ética, la estética, el sentido de la vida ${ }^{6}$.

Como plantean Allan Janik y Stephen Toulmin en su fascinante obra: La Viena de Wittgenstein, para llevar adelante una cabal sprachkritik era

${ }^{2}$ Ray Monk, Ludwig Wittgenstein, Anagrama, Barcelona, 1997, p. 442.

${ }^{3}$ Ray Monk, Ibid p. 274.

${ }^{4}$ Wittgenstein, Tractatus lógico-philosophicus, 6.421.

${ }^{5}$ Ibid, 6.421.

${ }^{6} \mathrm{El}$ diseño que llevó a cabo de la casa de su hermana Margareta, caracterizado por el despojamiento y la pureza arquitectónica, constituye un manifiesto de sus ideas estéticas y filosóficas contra todo tipo de falsa retórica. 
necesario encontrar una manera de reconciliar la física de Heinrich Hertz y Ludwig Boltzmann con la ética de Kierkegaard y Tolstoy; este era "el problema que preocupó originariamente a Wittgenstein y determinó la meta a la que iba dirigido su Tractatus" ". Desde esta perspectiva no hay discontinuidad entre el Tractatus Lógico-Filosófico y las Investigaciones Filosóficas. Ambas obras expresan las preocupaciones éticas de su autor: romper la teoría referencial del lenguaje y separar la ciencia de la ética, la esfera de la conducta de la esfera de la razón especulativa, dado que la moralidad no es contraria a la razón, pero sus fundamentos se encuentran en otra parte ${ }^{8}$. Refiriéndose al Tractatus Wittgenstein dice en una carta que escribe a Ludwig von Ficker (editor de la revista Der Brenner, a quien pide consejo para la publicación de su libro): "La intención del libro es ética. Pensé introducir en el prefacio una frase que no figura ahora, pero que les voy a reproducir aquí, porque tal vez les dará la clave de la obra. Lo que yo quería escribir era esto: 'Mi obra comprende dos partes: la que se presenta, más todo lo que no escribí. Y precisamente la segunda es la más importante'. Mi libro marca los límites de la esfera de la ética en algún modo desde el interior, y estoy convencido de que es la única manera rigurosa de trazarlos" ". La ética es un intento de decir lo indecible, de arremeter contra los límites del lenguaje, pero 'De lo que no se puede bablar, mejor es callarse"ro. La ética no se dice sino que se muestra en nuestros actos. La distinción entre un primer y un segundo Wittgenstein no es más que la consecuencia de la particular lectura que Russell hizo del Tractatus, y de los malentendidos que surgen de separar a un hombre de la cultura que lo constituye.

En Investigaciones Filosóficas, centrándose en la idea de lenguaje como comportamiento, sostiene que el significado de las palabras no remite ya a la función de representación sino al uso de los términos. Lo que intenta mostrar es la "prodigiosa diversidad" de modos en que los hombres usan el lenguaje. Afirma que nuestro lenguaje adquiere significación a partir de los usos que le damos en la práctica, dentro de reglas que regulan los usos de las

${ }^{7}$ Allan Janik y Stephen Toulmin, La Viena de Wittgenstein, Taurus, Madrid, 1998, p. 212.

${ }^{8}$ Ibid, p. 249-251.

${ }^{9}$ En Dominique Lecourt, El orden y los juegos, Ediciones de la Flor, Bs As, 1984, p. 176.

${ }^{10}$ Wittgenstein, Tractatuslógico-pbilosopbicus, 7. 
expresiones en los distintos juegos de lenguaje en el contexto de las formas de vida que organizan y dan sentido a dichos juegos. Las reglas son siempre públicas, dialógicas, se verifican al compartirlas ${ }^{11}$. En consecuencia todo lenguaje privado es imposible, el lenguaje es siempre público. Dado que el significado se establece en el contexto, desaparece la búsqueda del ideal de claridad de un lenguaje perfecto y unívoco. El uso implica los deslizamientos de sentido y las ambigüedades propias del comportamiento humano. El lenguaje ordinario es abierto y dinámico, en él no es posible definir sino sólo encontrar algunos parecidos de familia ${ }^{12}$. Las semejanzas o parecidos de familia no se estructuran como esencias fijas compartidas por los individuos o las cosas semejantes. Hay rasgos similares pero no son lo mismo, y en la repetición es donde aparece la huella de la diferencia. Son semejantes y, por eso mismo, diferentes.

Ningún límite es definitivo, permanentemente surgen nuevos juegos mientras otros se sedimentan y el hombre los comprende y usa dentro de las formas de vida en las que está inserto. Por tanto la certeza es siempre subjetiva y los acuerdos mera conjetura. La significación de la vida es un enigma que no puede ser resuelto racionalmente, en consecuencia la ética no se enseña argumentativamente sino a través de ejemplos de conducta, y esto es tarea del arte. Wittgenstein no reduce la complejidad de la acción sino que trata de hacerla plausible insertándola en el mundo práctico, en juegos de lenguaje que remiten al concepto de responsabilidad y compromiso, donde los valores son algo sobre lo que no se debe debatir sino actuar.

La misma vida de este gran pensador fue presa de las paradojas y confusiones del lenguaje: se lo consideraba en su época un genio filosófico a partir de equívocas interpretaciones de su obra alentadas por el hecho de que él mismo no acertó a explicar públicamente su rechazo a las mismas. Por otra parte como señalan Janik y Toulmin: "una de las peores desgracias que le pueden ocurrir a un escritor de gran seriedad intelectual y de fuertes ardores éticos es que Inglaterra 'naturalice' sus ideas ... los prejuicios con los que sus oyentes ingleses se le acercaban impedían a éstos casi por completo entender el punto sobre el que estaban hablando"13.

11 Wittgenstein, Investigaciones filosóficas, I 201-202.

12 Ibid, I 66-67.

13 Allan Janik y Stephen Toulmin, ibid, p. 21 y 25. 
La teoría de discurso de Ernesto Laclau y Chantal Mouffe recoge algunas de las ideas fundamentales del pensamiento de Wittgentein, las que constituyen aportes claves para pensar la sociedad y la política desde la perspectiva de una democracia radical y plural.

\section{Discursividad de lo social}

Para reflexionar sobre estas cuestiones, analizaremos en primer lugar el concepto de discurso desarrollado por Ernesto Laclau, cuya comprensión consideramos básica dentro del contexto de su teoría política, en tanto su pensamiento se articula en torno a dicha noción ${ }^{14}$.

Tomando un ejemplo inspirado en Wittgenstein, Laclau desarrolla su concepción del espacio social como discurso partiendo de la idea que toda configuración social es una configuración significante. En la construcción de un muro, nos dice, el acto de pedir un ladrillo es lingüístico, el ponerlo en la pared es extralingüístico. Pero esta distinción no agota la realidad de ambos actos. Las dos acciones comparten una operación total que es la construcción de la pared.

¿Cómo caracterizamos a esa totalidad que incluye, como momentos parciales, elementos lingüísticos y no lingüísticos? Esta totalidad es lo que llamamos discurso. Por discurso no se entiende, entonces, una combinación de habla y escritura, sino que, por el contrario, habla y escritura son tan sólo componentes internos de las totalidades discursivas. Por ejemplo, si pateo un objeto esférico en la calle, o si pateo una pelota en un partido de football, el hecho físico es el mismo, pero su significación es diferente. El objeto es una pelota de football sólo en la medida en que se establece un sistema de relaciones con otros objetos, y estas relaciones no están dadas por la mera referencia material de los objetos sino que son, por el contrario, socialmente construidas. Este conjunto sistemático de relaciones es lo que llamamos discurso.

El carácter discursivo de un objeto no implica poner su existencia en cuestión. Un objeto sólo es tal en la medida en que está integrado a un sistema de reglas socialmente construidas, esto no significa que deje de existir

${ }^{14}$ Ernesto Laclau, Nuevas reflexiones sobre la revolución de nuestro tiempo, Nueva Visión, Bs. As., 1993, p. 114. 
como objeto físico. La existencia de los objetos es independiente de su articulación discursiva. Debemos, entonces, diferenciar existente (el objeto aquí y ahora) de realidad (lo que se predica de ese objeto). Es decir, una piedra existe independientemente de todo sistema de relaciones sociales, pero es o bien un proyectil o bien un objeto de contemplación estética, etc, sólo dentro de una configuración discursiva específica. Un diamante en el mercado, o en el fondo de una mina, es el mismo objeto físico, pero sólo es una mercancía dentro de un sistema determinado de relaciones sociales. De lo anterior podemos concluir que la realidad es una construcción social en tanto se la construye al significarla. Por esta misma razón, es en la discursividad que se constituye la posición del sujeto como agente social y no el agente social el que es origen del discurso.

Partiendo entonces de la idea, sostenida por Wittgenstein ${ }^{15}$ de que la vida social supone el uso de determinados juegos de lenguaje los cuales expresan formas de vida, lo lingüístico y lo extralingüístico, lo social puede pensarse, entonces, como un espacio discursivo.

Como ya señalamos, a partir de Wittgenstein la separación entre significado y uso (semántica y pragmática) se ha tornado borrosa. El significado de una palabra es enteramente dependiente de su contexto. Toda identidad $\mathrm{u}$ objeto discursivo se constituye en el contexto de una acción y toda acción no lingüística también tiene un significado. " $\mathrm{La}$ distinción entre elementos lingüísticos y no lingüísticos no se superpone con la distinción entre 'significativo' y 'no significativo', sino que la primera es una distinción secundaria que tiene lugar en el interior de las totalidades significativas"16.

Los hechos naturales son también hechos discursivos en razón de que la misma naturaleza es ella el resultado de una construcción histórico-social. No hay ningún hecho cuyo sentido pueda ser leído de manera transparente, del mismo modo que no hay ningún hecho que pueda probar de modo definitivo una teoría, dado que no hay garantía de que ese hecho no pueda ser explicado de un modo más adecuado (es decir determinado en su sentido) por una teoría posterior y más comprensiva.

\footnotetext{
${ }^{15}$ Wittgenstein, Investigaciones Filosóficas, I 7.

${ }^{16}$ Ernesto Laclau, ibid. p. 116.
} 
La idea de que el ser de los objetos se construye discursivamente en el devenir, implica afirmar una ontología historicista, antiesencialista y posfundacionalista, dejando al descubierto la ilusión de los universales.

\section{Democracia, pluralismo y responsabilidad}

La democracia pluralista necesita de relaciones donde emerja la diversidad y la diferencia, y es en esta dirección, como lo plantean Ernesto Laclau y Chantal Mouffe, donde las ideas de los trabajos de Wittgenstein constituyen una contribución valiosa para el pensamiento democrático, en tanto aportan una alternativa que pone al descubierto las limitaciones de la concepción liberal de democracia. ${ }^{17} \mathrm{Su}$ permanente rescate de las múltiples, diversas e inconmensurables formas de vida y de lenguaje, su rechazo a las significaciones absolutas y a la categoría de sujeto trascendental, permite sostener dentro del campo de la política que los sujetos se constituyen en el juego de las relaciones sociales, entendidas éstas como relaciones significativas y de poder.

Como sostiene Mouffe, no se trata de extraer una teoría política de Wittgenstein, ni de intentar elaborar una en base a sus escritos, sino que la importancia de este autor reside en señalar un nuevo modo de teorización acerca de la política, que rompe con el modo de universalización y homogeneización que ha caracterizado a la mayoría de las teorías liberales, en tanto su filosofía es un intento de vivir aceptando la relatividad, la duda y la ausencia de Dios. Es decir, que es necesario un profundo desplazamiento en el modo de aproximarnos a las cuestiones políticas aceptando la existencia de multiplicidad de juegos de lenguaje, ninguno de los cuales posee un rol fundacional de nuestra vida política. La celeridad de los cambios y la multiplicidad de dimensiones que adquiere lo social hoy nos obliga a redefinir permanentemente las identidades desocultando los diversos juegos de lenguaje que operan en la constitución de las identidades. De acuerdo con las categorías de Wittgenstein, las instituciones democráticas deben ser vistas

17 Analizaré en este punto el trabajo de Chantal Mouffe, "Wittgenstein, Political Theory and Democracy" en The Democratic Paradox, London, Verso, 2000. La idea de democracia radical también es desarrollada por E. Laclau y Ch. Mouffe en Hegemonia y estrategia socialista. Hacia una politica democrática radical, Ed. Siglo XXI, 1987. 
como definiendo un posible juego, entre otros, del lenguaje político. En tanto aquellas no proveen una solución racional al problema de la coexistencia humana y dependen de cada contexto histórico, resulta inadecuado pretender dar un fundamento racional a los principios democráticos. La democracia no requiere una teoría de la verdad universal ni de nociones como validez incondicionada, sino múltiples prácticas y movimientos pragmáticos intentando persuadir a la gente de ensanchar el campo de sus compromisos y acuerdos con otros, en orden a construir una comunidad más inclusiva. Desde Wittgenstein sabemos que todo acuerdo de opiniones es primero un acuerdo en el lenguaje a usar, y que éstos constituyen también acuerdos en formas de vida. Es a partir de estos acuerdos que los hombres deciden lo que es verdadero o falso. Las reglas, para Wittgenstein, son siempre simplificaciones de prácticas, y ellas son inseparables de formas específicas de vida. En consecuencia lo procedimental y lo substancial son inseparables, en el sentido, por ejemplo, de que la justicia procedimental supone la aceptación de ciertos valores, ya que los procedimientos siempre envuelven compromisos éticos substanciales. Las instituciones democráticas y una concepción democrática de justicia, requieren de un ethos democrático para funcionar apropiadamente y mantenerse.

La sociedad democrática no puede pensarse como aquella que hubiera alcanzado el ideal de la armonía perfecta en las relaciones sociales. La democracia sólo puede existir en tanto ningún grupo o agente social pueda arrogarse el derecho de que el lugar del poder le sea consubstancial y se erija en representante de la totalidad ${ }^{18}$. El poder y las luchas por el poder son parte constitutiva de la democracia, y esta existe a condición de que todos acepten el carácter particular y limitado de sus reivindicaciones. El poder es ineliminable y sólo desde esta perspectiva es posible pensar el pluralismo. La democracia no sólo peligra cuando no hay posibilidad de alcanzar algún consenso respecto de sus instituciones y los valores en que se sustenta, sino también cuando su dinámica de lucha aparece negada por la emergencia de un aparente consenso sin grietas. La desaparición de las diferencias entre los partidos políticos no es el resultado de una supuesta madurez política sino, en la mayoría de los casos, expresión de un vacío de poder que rápidamente puede ser ocupado por ideologías totalitarias.

${ }^{18}$ Claude Lefort, La invención democrática, Nueva Visión, Bs. As., 1990. 
No es ofreciendo sofisticados argumentos racionales y construyendo verdades trascendentes acerca de la superioridad de la democracia liberal, que los valores democráticos pueden ser fomentados ${ }^{19}$. La formación de subjetividades democráticas, afirma Mouffe, es una cuestión de identificación con valores democráticos, y esto es un complejo proceso que tiene lugar a través de múltiples prácticas, discursos y juegos de lenguaje. Para la concepción del pluralismo agonístico inspirado en Wittgenstein, una de las ideas fundamentales es comprender qué significa seguir una regla (dado que no consiste en interpretarla en determinado sentido, ni en comprender una teoría, sino en la habilidad para usarla en diferentes circunstancias) y reconocer la diversidad de modos en los cuales el juego democrático puede ser jugado, en lugar de tratar de reducir la diversidad a un uniforme modelo de ciudadano. Esto significa promover una pluralidad de formas de ser un ciudadano democrático y la creación de instituciones que hagan posible seguir las reglas democráticas en pluralidad de modos. Wittgenstein nos enseña que no hay un único camino, y es precisamente este reconocimiento constitutivo de un pluralismo democrático. La obediencia a las reglas democráticas debe ser inscripta en muy diferentes prácticas. La ciudadanía democrática puede tomar muchas formas diversas y tal diversidad lejos de ser un peligro para la democracia, es de hecho su verdadera condición de existencia. Esto sin duda generará conflictos y enfrentamientos, pero éstas no serán luchas entre enemigos sino entre adversarios, en tanto todos los participantes reconocerán las posiciones de los otros como legítimas. Tal comprensión de la política democrática es lo que Chantal Mouffe llama precisamente pluralismo agonístico.

Desde esta perspectiva, ninguna decisión puede ser simplemente presentada como mera aplicación de procedimientos y justificada como el único movimiento que nosotros podríamos hacer en esas circunstancias. Wittgenstein, fiel a las preocupaciones éticas que marcaron toda su vida, nos enseña que nunca deberíamos escapar a la responsabilidad por nuestras decisiones invocando la orden de reglas o principios generales. Lo que su filosofía ejemplifica no es la búsqueda de certidumbre sino la búsqueda de

${ }^{19}$ Wittgenstein, Investigaciones Filosóficas, I 241: “¿Dices, pues, que la concordancia de los hombres decide lo que es verdadero y lo que es falso? Verdadero y falso es lo que los hombres 'dicen'; y los hombres concuerdan en el 'lenguaje'. Ésta no es una concordancia de opiniones, sino de formas de vida". 
responsabilidad, y lo que él nos muestra es que formular una demanda es hacer una afirmación, y esto es algo por lo cual los hombres deben ser responsables. Este énfasis en la decisión y la responsabilidad nos permite imaginar políticas democráticas en un camino diferente, porque subvierte la tentación siempre presente en las sociedades democráticas de disfrazar formas existentes de exclusión bajo el velo de la racionalidad o la moralidad. Evitando la posibilidad de una completa reabsorción de la alteridad dentro de la unidad y la armonía, esta insistencia en la necesidad de dejar el debate acerca de la justicia por siempre abierto, establece las bases para un verdadero proyecto de democracia radical y plural.

Mouffe sostiene también que hay puntos de convergencia entre Wittgenstein y Derrida acerca de las ideas de indecidibilidad y responsabilidad ética. Ambos filósofos nos proveen un nuevo modo de pensar la democracia fundamentalmente diferente del enfoque racionalista dominante. Para estos pensadores la comprensión de la responsabilidad requiere que abandonemos el sueño de total dominio y la fantasía de que podríamos escapar a nuestras formas de vida. Sin duda debe reconocerse que en orden a impedir el cierre del espacio democrático, es necesario abandonar cualquier referencia a la idea de un consenso que, porque estaría fundado en la justicia y racionalidad, no podría ser desestabilizado. El principal obstáculo para alcanzar una visión democrática radical pluralista lo constituye la equivocada búsqueda de consenso y reconciliación, y esto es algo que Wittgenstein, con su insistencia en la necesidad de respeto de las diferencias, destaca de una manera poderosa. Por otra parte "lo indecidible no es sólo la oscilación entre dos significaciones o reglas contradictorias... Indecidible es la experiencia de lo que siendo extranjero, heterogéneo con respecto al orden de lo calculable y de la regla... debe sin embargo entregarse a la decisión imposible, teniendo en cuenta el derecho y la regla" 20 . Un pensamiento democrático que incorpora estos aportes puede ser, sin duda, más receptivo a la multiplicidad de voces (y la necesidad de expresarlas) y a la complejidad de las estructuras de poder que una sociedad pluralista entraña, que a los esfuerzos por alcanzar armonía y consenso.

${ }^{20}$ Jacques Derrida, Fuerza de ley. El 'fundamento mistico de la autoridad', Tecnos, Madrid, 1997 , p. 55. 
Una democracia radical y plural implica: 1) la necesidad de reconocimiento del otro y la imposibilidad de anular las diferencias, y 2) la aceptación del antagonismo, como una dimensión propia del campo de la política, y el momento de la decisión como característico de dicho campo, decisión que estructura las relaciones sociales y es siempre tomada en un terreno indecidible, lo cual acarrea siempre un elemento de fuerza y violencia que nunca puede ser eliminado y tampoco puede ser adecuadamente aprehendido a través solamente del lenguaje de la ética. Esto no significa que la política deba ser disociada de las preocupaciones éticas, sino que la relación entre ambas debe entenderse de un modo diferente, en tanto no puede darse sin problematizar la naturaleza de la sociabilidad humana. Si, como observamos cotidianamente, rivalidad, violencia y egoísmo son una posibilidad siempre presente en la naturaleza humana (y nuestro mundo presente es, lamentablemente, una clara confirmación de ello), reciprocidad y hostilidad no pueden ser disociadas, ya que todo orden social estará siempre amenazado por la violencia. Negarnos a reconocer que la violencia es inerradicable, vuelve a la teoría democrática incapaz de comprender la dimensión de antagonismo propia de lo político.

Según Ch. Mouffe debemos sostener una ética que reconozca los límites de la razón, la pluralidad de valores y el carácter hegemónico de los consensos alcanzados. La violencia es inherente a la sociabilidad y ningún contrato o diálogo puede eliminarla totalmente, porque ella constituye una de sus dimensiones. No es a través de su negación que la política democrática va a ser alcanzada. Por el contrario, es reconociendo las tendencias contradictorias existentes en los intercambios sociales y la fragilidad de todo orden democrático, que seremos capaces de comprender la tarea fundamental de la confrontación democrática: de qué modo transformar en agonismo el potencial antagonismo existente en las relaciones humanas. "La idea de una sociedad completamente emancipada y transparente, de la que se habría eliminado todo movimiento tropológico entre sus partes constitutivas, implica el fin de toda relación hegemónica ( $\mathrm{y}$ además, como veremos más adelante, de toda política democrática)"21.

${ }^{21}$ Judith Butler, Ernesto Laclau, Slavoj Zizek, Contingencia, begemonia, univerdalidad, F.CE, Bs. As. 2003, p. 63. 
Al hablar de los niveles de radicalización teórica de la categoría de hegemonía, Laclau recurre a un ejemplo inspirado en Wittgenstein, para mostrar que la regla misma es indecidible en términos de serie enunciada en cuanto tal, y puede ser permanentemente transformada, pero en tanto la serie es indecidible en relación a su misma estructura formal, el acto hegemónico no será la realización de una racionalidad estructural que lo precede sino un acto de construcción radical. La contingencia propia de la articulación hegemónica es efecto de la ambigüedad y del carácter incompleto de la estructura, como resultado no de la imposibilidad empírica de alcanzar su coherencia específica, sino de algo que reside en el interior de la estructura como tal.

Como la deconstrucción ha mostrado, un punto de vista imparcial es de hecho estructuralmente imposible, en tanto la indecidibilidad forma parte de la construcción de toda forma de objetividad. Si como afirma Derrida, differance es la condición de posibilidad de constitución de toda unidad y totalidad y al mismo tiempo su límite, esto nos lleva a reconocer que la alteridad y la multiplicidad son irreductibles. Desde esta perspectiva, sin recurrir al concepto de indecidibilidad es imposible pensar y debatir acerca de las ideas de decisión política y responsibilidad ética. Toda decisión implica elección, riesgo, negación de otras alternativas y también la apertura de posibilidades y todo consenso es siempre inestable y caótico, ya que una permanente estabilidad significaría el fin de la política y la ética.

De esto surge la imposibilidad conceptual de la democracia entendida como justicia y armonía plena, en tanto reconciliación completamente alcanzada. En consecuencia, la democracia debe ser concebida como un bien que existe como bien, sólo en tanto no pueda ser plenamente lograda. Una democracia pluralista, que parte del reconocimiento de la multiplicidad de ideas de bien es irreductible, debe asumir el desafío de enfrentar qué hacer con la violencia y cómo tratar los antagonismos. Estas constituyen cuestiones éticas con las que una política pluralista democrática se verá confrontada permanentemente, y para la cual nunca habrá una solución final. En consecuencia la democracia, en tanto búsqueda de justicia, libertad e igualdad postulada pero nunca plena y definitivamente alcanzada, constituye un permanente desafío. 
Como concluye Chantal Mouffe en su trabajo "The Ethics of Democracy"22: reconocer el necesario hiatus entre ética y política y la irreductible tensión entre igualdad y libertad, entre la ética de los derechos humanos y la lógica política, la cual conlleva el establecimiento de fronteras, con la violencia que ello implica, significa reconocer que el campo de la política no es reducible a un cálculo moral racional, ya que siempre requiere de decisiones. Desechar la ilusión de una posible reconciliación de ética y política, aceptar la permanente interrogación de la política por la ética, este es, sin duda, el único modo de reconocer la paradoja democrática.

El pluralismo de valores conlleva el reconocimiento de la dimensión conflictiva de la democracia, la cual nunca puede ser completamente eliminada sino sólo domesticada o sublimada. Es a partir de las tendencias contradictorias, puestas en movimiento a través de la interacción social y de la consecuente fragilidad de todo orden democrático, que seremos capaces de transformar el antagonismo, existente en las relaciones humanas, en agonismo. El reconocimiento del otro, el respeto de las diferencias, la aceptación del disenso, la formación de subjetividades democráticas y la extensión de estas prácticas a todas las esferas de la vida social, permitirá avanzar en la construcción de una democracia radical y plural, sin que olvidemos que la condición de posibilidad de una democracia pluralista es, al mismo tiempo, la condición de imposibilidad de su perfecta implementación. Este fracaso de la sociedad en constituirse como tal, es lo que hace posible la interacción democrática. Aquí reside el reconocimiento de la naturaleza paradójica de la democracia que no debe ser considerara como algo natural, o resultado de la evolución moral de la humanidad, sino como un campo permanente de conflicto cuyos efectos son siempre inciertos y precarios. Advertidos contra la ilusión de que una democracia puede ser completamente alcanzada, esto nos fuerza a mantener viva la resistencia democrática. Es en este sentido que la propuesta de Laclau y Mouffe de una democracia radical y plural, debe ser tomado como un aporte clave para la construcción de sociedades democráticas.

${ }^{22}$ Chantal Mouffe, The Democratic Paradox", Verso, London, 2000, p. 140. 


\section{Algunas reflexiones}

La contingencia y la incertidumbre de nuestras vidas es el precio que debemos pagar por nuestra libertad, por nuestra capacidad de intervenir en el mundo; esta es nuestra condición ontológica, nuestra fuerza, no nuestra debilidad. Ningún sentido está fijado a priori ni fundado de manera trascendente y el futuro reabre permanentemente el pasado en la discursividad del presente. Al acercamos a la vida y al pensamiento de Wittgenstein nos encontramos con un hombre a la vez deslumbrante y extraño, profundamente preocupado por una visión pesimista del destino de la humanidad y por problemas éticos que se vuelven especialmente significativos para él, a partir del entorno histórico y cultural de la Viena de comienzos del siglo XX, la primera Guerra Mundial y la terrible experiencia, después, del nazismo y la Segunda Guerra Mundial. Hoy muchas décadas más tarde, y al comienzo de un nuevo milenio, seguimos debatiéndonos entre preocupaciones morales y una visión pesimista acerca del destino del hombre. Las terribles guerras e injusticias del presente nos muestran que nada hemos aprendido, y que no es posible escapar a los más sombríos aspectos de la condición humana si permanecemos atrapados en una sociedad donde el poder, el egoísmo, la competencia y el individualismo más descarnado siguen siendo los valores dominantes. Volver a Wittgenstein, a su vida y su tiempo, constituye una experiencia que nos desgarta y moviliza a la vez, en tanto parece mostrarnos que no hay lugar para la esperanza, aunque sin embargo la hay.

La perplejidad frente al futuro, un futuro que ya no está garantizado por la idea de progreso, genera miedos y angustia: Vivimos sin duda una época de transición en la cual, la crisis del Estado y de los partidos políticos, y los límites de la democracia representativa, hacen necesario ir construyendo otras formas de organización, nuevas experiencias de democracia participativa y plural, que permitan el debate y la constitución de subjetividades e instituciones capaces de avanzar hacia formas de sociabilidad más equitativas. La humanidad se enfrenta a grandes desafíos ¿seremos capaces de darles respuestas en pos de un mundo más justo?

\section{Resumen}

La teoría de discurso de E. Laclau y Ch. Mouffe retoma las categorías de juegos de lenguaje' y 'formas de vida' a fin de elaborar su concepción de discurso y pensar la 
democracia. En tanto la filosofía de Wittgenstein constituye un intento de vivir aceptando la relatividad, la duda y la ausencia de Dios, permite romper con el modo de universalización y homogeneización que ha caracterizado a la mayoría de las teorías liberales y aceptar que el poder y las luchas por el poder son parte constitutiva de la democracia, poniendo de este modo el acento en la decisión y la responsabilidad. El respeto de las diferencias, la aceptación del disenso y la extensión de estas prácticas a todas las esferas de la vida social, permitirá avanzar en la construcción de una democracia radical y plural.

Palabras clave: "Laclau", "Mouffe", "Wittgenstein"

\begin{abstract}
E. Laclau and Ch. Mouffe's theory of discourse retakes the categories of "language games" and "forms of life" in order to elaborate his conception of discourse and think democracy. Inasmuch Wittgenstein's philosophy constitutes an attempt to live accepting relativity, doubt and the absence of God, it allows for the breaking up with the way of universalization and homogenization that has characterized the majority of liberal theories and for the acceptance that power and struggles for power are constituent part of democracy, laying stress in this way on decision and responsibility. Respect of differences, acceptance of dissent and the extension of these practices to all spheres of social life, will allow us to proceed towards the construction of a radical and plural democracy.
\end{abstract}

Key words: "Laclau", "Mouffe", "Wittgenstein" 